\title{
Effects of High Intensity Interval Training Using Ifittkids Module on Memory Strength, Attention and Aerobic Capacity
}

Vadivelan Lohonathan, Siti Hartini Azmi, Norhazira Rahim

To Link this Article: http://dx.doi.org/10.6007/IJARBSS/v11-i12/11826

DOI:10.6007/IJARBSS/v11-i12/11826

Received: 14 October 2021, Revised: 17 November 2021, Accepted: 01 December 2021

Published Online: 22 December 2021

In-Text Citation: (Lohonathan et al., 2021)

To Cite this Article: Lohonathan, V., Azmi, S. H., \& Rahim, N. (2021). Effects of High Intensity Interval Training Using Ifittkids Module on Memory Strength, Attention and Aerobic Capacity. International Journal of Academic Research in Business and Social Sciences, 11(12), 873-888.

Copyright: @ 2021 The Author(s)

Published by Human Resource Management Academic Research Society (www.hrmars.com)

This article is published under the Creative Commons Attribution (CC BY 4.0) license. Anyone may reproduce, distribute, translate and create derivative works of this article (for both commercial and non0-commercial purposes), subject to full attribution to the original publication and authors. The full terms of this license may be seen at: http://creativecommons.org/licences/by/4.0/legalcode

Vol. 11, No. 12, 2021, Pg. $873-888$

Full Terms \& Conditions of access and use can be found at http://hrmars.com/index.php/pages/detail/publication-ethics 


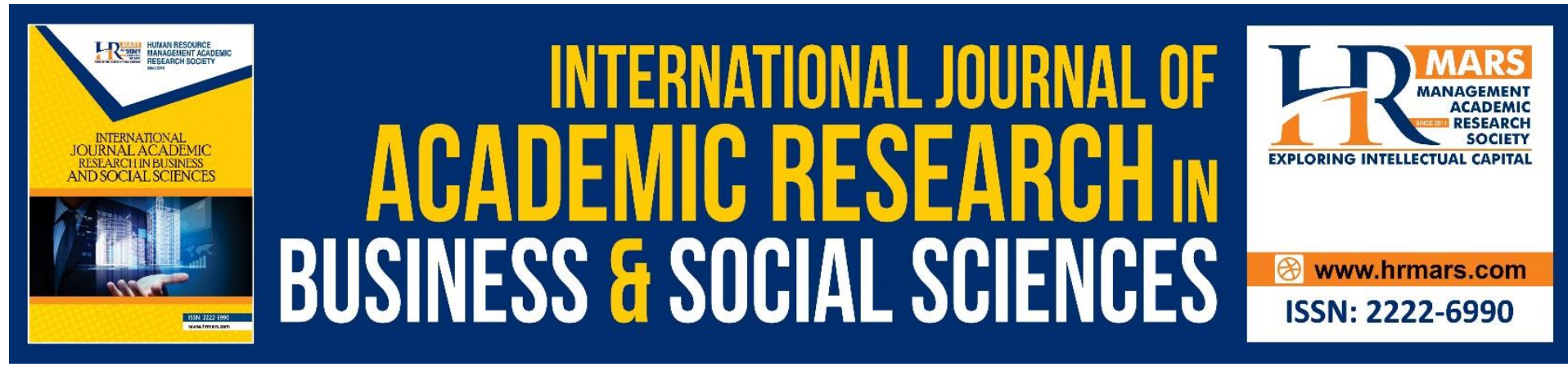

\title{
Effects of High Intensity Interval Training Using Ifittkids Module on Memory Strength, Attention and Aerobic Capacity
}

\author{
Vadivelan Lohonathan, Siti Hartini Azmi, Norhazira Rahim \\ Department of Health Sciences, Faculty of Sports Science and Coaching, Sultan Idris \\ Education University (UPSI), Tanjung Malim, 35900, Perak, Malaysia
}

\begin{abstract}
Executive function, attention, and memory are an important indicator of cognitive health of children. Cardiovascular fitness has a positive relationship with cognitive function performance. IFITTKIDS module is a training programme guided by High Intensity Interval Training (HIIT) used to see the effect on memory strength, attention and aerobic capacity. This HIIT training is able to increase the fitness level optimally in a short period of time. This study was conducted quantitatively using a 'Pre and post control group design'. The study subjects consisted of 64 primary school students aged 11 years who were divided into two groups namely 32 participants in the treatment group and 32 in the control group. The intervention was conducted for 12 weeks with a training frequency of two times a week for 20 minutes per session. The results using ANCOVA test analysis showed that by adjusting the pre-test score as a covariate, the post-test score for memory strength, attention and aerobic capacity of the treatment group was significantly higher with the score from the control group with $F(1.61)=68.15, p<.05$, and eta squared $=.53, F(1,61)=54.906, p<.05$, eta squared $=$ .47 and $F(1.61)=63,987, p<.05$, and eta squared $=.51$. Substantially, the findings of this study show that HIIT training guided by IFITTKIDS MODULE for 8 weeks is productive in improvising aerobic capacity and memory strength in 11-year-old school children. The results of this study, recommend that this IFITTKIDS MODULE can be used as one of the training programme to increase the level of memory strength, attention and aerobic capacity in children.
\end{abstract}

Keywords: High Intensity Interval Training (HIIT), Memory Power, Aerobic Capacity, Physical Education

\section{Introduction}

As many as $39 \%$ of all children in Malaysia are inactive physically and 424,000 children have health problems in Malaysia (NHMS, 2019). Physical inactivity is the fourth leading risk factor for death globally (Malina, 1996; World Health Organization, 2019). There are 3.9 million adolescents aged 18 and above with diabetes in Malaysia (NHMS, 2019). A sedentary lifestyle during childhood will not only influences physical health, but cognitive health. That is, accumulating evidence suggests that low involvements in physical activity and aerobic fitness are associated with declines in academic achievement, cognitive abilities, brain structure, and 
brain function ( Mora-Gonzalez et al., 2019; Castelli et al., 2007; Kim, et al., 2010; Hillman et al., 2008; Pontifex et al., 2011; Chaddock et al., 2011).

In recent years HIIT training has become a popular physical activity among athletes and fitness practitioners to improve fitness to an optimal level. Cardiovascular fitness has a positive relationship with cognitive function performance (de Greeff et al., 2018; Raine et al., 2016; Drollette et al., 2015; Buck et al., 2008). Aerobic exercise improves brain cognitive function and nerve performance in the brain (El-Sayes et al., 2018). Frequent involvement of physical activity and fitness are the best methods for improving cognitive function and memory strength in children (Erickson et al., 2015; Khan \& Hillman, 2014). Physical fitness is an indicator that can be used to assess memory strength (Canepa et al., 2020). There is sufficiet evidence that physical activity has a positive relationship to cognitive function and academic performance in children (Donnelly et. al., 2016; Mura et al., 2015; Vazou et al., 2016; EstebanCornejo et al., 2015; Bass et al., 2013). Aerobic exercise for 20 minute increases memory strength (Kao et al., 2020; Chang et al., 2012; Papp et al., 2014; Scherder et al., 2014). One of the cognitive aspects that has been the concern of researchers is to see the relationship between motor skills and memory strength (Hsieh et al., 2017; Herrmann, et al., 2018). Physical activities based on cardiovascular intervention programmes and motor skills' physical training for 10 weeks systematically improved memory strength of children (Koutsandreou et al., 2016; Lin et al., 2021).

According to Tomporowski et al (2011), brain cognitive functions can be classified into perception, concentration, memory, working memory, brain executive function, concept formation and reasoning, intelligence, and academic achievement. Memory is a systematic process that involves the active storage, maintenance, and manipulation of information retrieved over short intervals (Postle, 2006). Memory strength is the most crucial cognitive aspects in planning and problem solving (Postle, 2016). It's been discovered that there is a productive relationship between increased physical activity with brain cognitive function especially short-term memory strength and concentration among school children (Sujatha et al., 2020; Leahy et al., 2020; Moreau \& Chou, 2019; Rassovsky \& Alfassi, 2019; Rao, Vhavle \& Manjunath 2019). Physical exercise and activities that improvise magnitude of brain is derived neurotrophic factor (BDNF) in the cerebral cortex and hippocampus which have a very high association in enhancing learning performance, concentration and memory strength (Farmer et al., 2004; Berchtold et al., 2010). Regular physical exercise can produce new neurons in the hippocampus that are important in enhancing learning performance and memory strength (Curlik and Shors, 2013; Déry et al., 2013).

Typically, HIIT training can be defined as an exercise which consists of several movements that is alternate between high -intensity exercise in the range of 85 to 95 percent of the maximum pulse rate or maximum oxygen consumption and followed by rest or active rehabilitation activities (Gibala, \& McGee, 2008; Little et al., 2011). There are two types of HIIT training, which are resistance HIIT training and aerobic HIIT training. HIIT resistance training is interval training that includes body movements, weight objects, barbells, or resistance training equipment, while aerobic HIIT training is intermittent training which uses traditional aerobic training (such as walking or cycling) (Kilpatrick, Jung, and Little, 2014). HIIT training designated into various forms and the most effective method of improving cardiorespiratory and metabolic function, thus improving the physical performance of athletes (Buchheit \& Laursen, 2013). HIIT training is seen as an enjoyable exercise compared to traditional medium-intensity training which is performed continuously (Bartlett et al., 2011). The problem of time constraints is the common reason given by society for not 
engaging in sports and fitness activities (Frazão et al., 2016; Thum et al., 2017; Heinrich et al., 2014). High Intensity Interval Training is used as an alternative aerobic exercise that could improve body health and brain function (Cvetković et al., 2018; Moreau \& Chou, 2019).

HIIT training could accomplish the improvisation of Peripheral Vascular function which encourages the cardiovascular system to adapt to high aerobic exercise intensity (Cvetković et al., 2018). Manipulation of intensity in aerobic exercise has been shown to have beneficial effects on cognitive and executive function of the brain (Kao et al., 2019; Kao et al., 2018; Crova et al., 2014; Gallotta et al., 2015; Pesce et al., 2013; Pesce et al., 2016; Schmidt et al., 2015; van der Niet et al., 2016; Knaepen et al., 2010; Niet, Smith et al., 2015; Moreau et al., 2017 Davis et al., 2011). HIIT training comes in various forms and is the most implicit method of improving cardiorespiratory and metabolic function. Hence, improving the physical performance of athletes (Buchheit \& Laursen, 2013).

Physical Education is a platform where students learn sports, fitness skills and explore new physical activities at the outdoors (Chandler \& Stringer, 2020). A 15-minute HIIT activity with adequate rest intervals can improve fitness and health (Chandler, 2020). This HIIT activity is the safest activity that can be carried out by children and is suitable to be carried out at the school level (Chandler, 2020). HIIT training is more constructive in terms of time utilisation because studies show that HIIT training results in greater improvement compared to traditional endurance training which increase aerobic fitness and maximum oxygen consumption despite using shorter training volume and duration (Zapata-Lamana et al. al., 2019; Wisløff et al., 2007; Burgomaster et al., 2008; Milanović, Sporiš, \& Weston, 2015). HIIT physical activity interventions in Physical Education among children can optimally improve fitness levels (Dobbins et al., 2013).

Indeed, there is a need to conduct high-intensity interval training (HIIT) physical training over a short period of time to improve fitness performance (Gibala et al., 2006; Lonsdale et al., 2013; Moreau et al., 2017). Children in schools need an effective training programme framework with short training periods to improve fitness (Lonsdale et al., 2013). The purpose of this study was to evaluate the effectiveness of HIIT training based on the IFITTKID Module to boost the performance of memory strength, concentration and aerobic capacity among 11-year-old students.

\section{Materials and Methods}

This study was conducted based on quantitative method with Pre and Post control group in which is an 8-week intervention training programme with pre and post tests to determine the outcome of using IFITTKIDS Module on memory strength, concentration and aerobic capacity. Study participants was 64 healthy 11 -year -old male and female students in total. Participants were divided into two groups which are treatment group $(n=32)$ and control group $(n=32)$. Participants of this study involves healthy 11 -year-old male and female students. All participants were primary school students from two schools in the Sepang District. All participants were free of health problems and had undergone a screening test of readiness to perform physical activity using the PAR Q questionnaire (Thomas, Reading, \& Shephard, 1992) to detect potential risks that may occur during training. The study protocol was described orally and written consent to participate in the study was also obtained from all participants.

\section{Cognitive Tests}

Based on previous research in adults, the anticipated cognitive performance effects following maximal exercise resided in areas of memory and attention (Covassin et al., 2007; Lo Bue- 
Estes et al., 2008; Moore et al., 2012; Abraham, George, \& Kunnath 2016; Moreau et al. al., 2017).

\section{Digit Span Test}

The 'Digit Span Test' is widely used as neuropsychological test to assess cognitive ability in aspects of short-term memory strength (Youngjohn et al., 1992; Richardson, 2007; Wambach et.al. 2011; Abraham et al., 2016; Moreau et al. al., 2017). There are 2 types of 'Digit Span Test' namely 'Forward Digit Span' and 'Backward Digit Span'. The 'Digit Span Test' using a computer to measure the strength of short-term memory has high values of accuracy and reliability (Woods et al., 2011). Pupils answer each 'Digit Span Test' item within the allocatted time period. Pupils have to type the numbers seen on the computer screen in the correct order using the computer keyboard. Pupils answer 40 'Forward Digit Span Test' questions. The series of numbers range from 1 to 9 . These series of numbers are arranged in ascending order from 2-digits (2-5; 6-3; 4-7) to 5-digits (6-9-1-6-3; 3-1- 7-9-5; 3-8-2-9-5) only. Pre and post test scores were recorded upon completion of the 'Digit Span Test' test.

Stroop Word Colour Test

The 'Stroop Word Color Test' is widely used as neuropsychological test to assess cognitive ability in aspects of concentration adapted from past studies (Stroop, 1935; Golden's 1978; Golden et al., 2003; Zimmermann et al., 2015; Scarpina \& Tagini, 2017; Sañudo et al., 2020).

\section{Progressive Aerobic Cardiovascular Endurance Run (PACER)}

Progressive Aerobic Cardiovascular Endurance Run (PACER) is one of the methods used in FITNESSGRAM to measure aerobic capacity. The PACER test allowed participants to adapt systematically by increasing the repetition capacity of the run according to the physiological appropriateness of the response. The PACER test has high validity in assessing aerobic capacity (Chun et al., 2000; Suminski et al., 2004; Burns et al., 2014). This test involves a method of continuous running between two distances of 20 meters where the 'beep' time will be faster at each level. The subject has to cross the line at a distance of 20 meters and wait until the next beep to continue the run. Subjects had to continue running according to their ability until they could not keep up with the 'beep' sound. When the subject is unable to keep up with the 'beep' for the second time then the test against him is terminated.

\section{IFIITKIDS Module Intervention Program}

In this study, the IFITTKIDS Module is used as an alternative training programme in Physical Education classes to improve memory, concentration and aerobic capacity. The training procedure started with a briefing session on the protocol of training programme to the participants. Treatment group participants went through HIIT training using IFITTKIDS Module for 8 weeks during Physical Education class under the supervision of Physical Education teacher for 30 minutes twice a week ( 5 minutes warm -up; 5 minutes cool -down; 20 minute exercises guided by IFIITKIDS Module). While the control group subjects went through continuous aerobic exercise under the supervision of Physical Education teacher for 30 minutes twice a week ( 5 minutes warm -up; 5 minutes cool -down; 20 minute exercises guided by continuous aerobic exercise. This training programme uses the concept of Tabata training on a ratio of 1: 2 between training time and rest time which is 10 seconds of rest and 20 seconds of training. The total duration of training is 20 minutes, 5 minutes of warm up and 5 minutes of cooling down. Pre-test score of memory strength, concentration and aerobic capacity were taken before subjects performed intervention training for both groups. At the 
end of 8 weeks, the level of memory strength, concentration and aerobic capacity of the treatment and control groups of each participant from both groups were measured again (post-test).

\section{Results}

In this study, Statistical Package for the Social Science for Windows (SPSS) version 26.0 computer software was used to analyse the data. Before the data were analysed, a data review process was made to detect errors or data loss by checking the frequency output from the descriptive analysis for each variable measured. In addition, data exploration has also been done to meet the general assumptions of each statistical analysis used. The normality of the data was examined using Shapiro-Wilk and Kolmogorov-smirnov statistics. ANCOVA (Analysis of Covariance) analysis was used to determine the existence of differences in aspects of memory strength and aerobic capacity between the treatment group and the control group by controlling for pre-test scores as covariates. The significance level was set at $p \leq 0.05$.

\section{Findings}

Table 1. Demographics of study participants in the form of frequency and percent

Gender

\begin{tabular}{llll} 
& Frequency & Percent & Std. Deviation \\
\hline Boys & 32 & 50.0 & .50 \\
Girls & 32 & 50.0 & \\
\hline Total & 64 & 100.0 &
\end{tabular}

Table 2. Pre -test and post -test scores for the control group and the experimental group in the form of mean and standard deviation

\begin{tabular}{lllll}
\hline \multirow{2}{*}{ Varaiable } & Pre test & & Post test \\
\cline { 2 - 5 } & Control & Experimental & Control & Experimental \\
& Mean (SD) & Mean (SD) & Mean (SD) & Mean (SD) \\
Memory strength & $53.52(5.57)$ & $57.12(5.78)$ & $66.53(5.15)$ & $76.69(3.72)^{*}$ \\
Attention & $63.50(5.51)$ & $67.00(5.78)$ & $75.94(4.66)$ & $85.34(4.56)^{*}$ \\
Aerobic capacity & $24.02(1.56)$ & $24.92(1.33)$ & $27.33(1.74)$ & $30.81(1.41)^{*}$ \\
(ml-kg.min) & & & & \\
\hline
\end{tabular}

Memory strength, attenion, capacity aerobic

* Differences in pretest and posttest scores between control and experimental groups with significant values $(P \leq 0.05)$. 


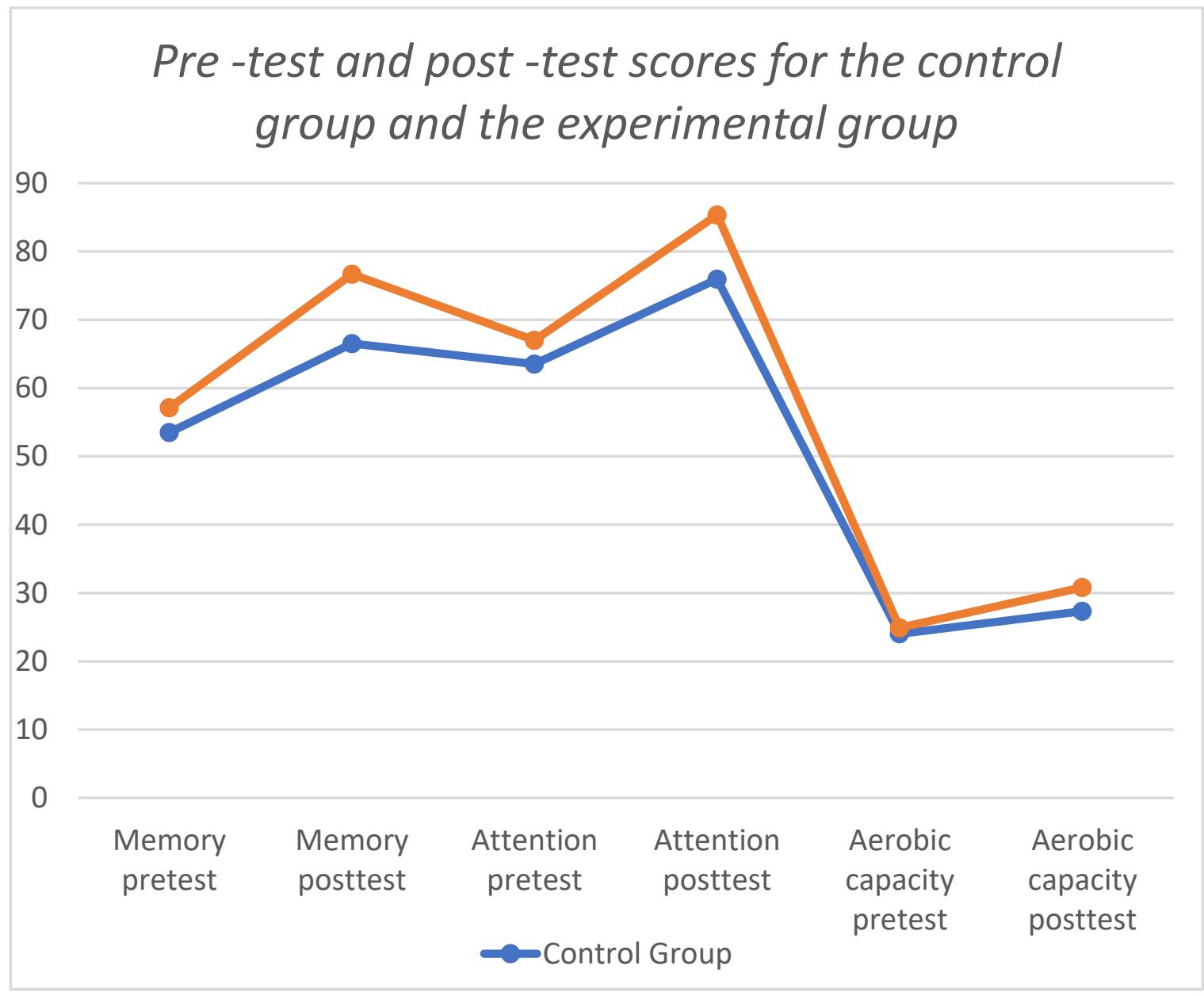

Descriptive statistical results showed that the mean post-memory test values for the treatment group (76.6969 \pm 3.72105$)$ surpassed the control group (66.5250 \pm 5.14793$)$. For the aspect of concentration, the mean post-test memory value for the treatment group $(85.3438 \pm 4.55511)$ surpassed the control group $(75.9375 \pm 4.65547)$ and the aerobic capacity score for the treatment group $(30.8125 \pm 1.41666)$ surpassed the control group $(27.3313 \pm$ 1.74253). One -way ANCOVA analysis was conducted to compare the effectiveness of the IFITTKIDS Module between the intervention group and the control group performing the 'Continuous Aerobic Exercise' exercise. ANCOVA assumptions are carried out first to ensure that it does not violate the assumptions of normality, linearity. homogeneity of variances, homogeneity of regression slopes and reliable measurement of the covariate. After controlling for the pre-test score, then statistical analysis showed that there was a significant difference on the post-test score of memory strength between the treatment group and the control group. $F(1.61)=68.15, p<.05$, and squared $=.53$. For concentration, statistical analysis showed that there was a significant difference on the post-test score of concentration between the intervention group and the control group. $F(1.61)=54.906, p<.05$, and squared $=.47$. Meanwhile, statistical analysis showed that there was a significant difference on the post-aerobic capacity score between the intervention group and the control group. $F(1.61)=$ $63,987, p<.05$, and squared $=.51$. These findings prove that the score of the treatment group using the IFITTKIDS Module recorded a higher score than the score of the control group in terms of memory strength, concentration and aerobic capacity. 


\section{Discussion}

This study intended to evaluate the effects of HIIT training guided by the IFITTKID Module for 8 weeks on memory strength, concentration and aerobic capacity. The findings of this study showed that children in the treatment group recorded a good improvement in memory strength, concentration and aerobic capacity. The findings of this study are in line with several previous studies that used the concept of HIIT training in their study. Findings of studies (de Greeff et al., 2018; Raine et al., 2016; Drollette et al., 2015; Buck et al., 2008) prove an increase in high-intensity aerobic physical activity improves brain fitness and executive function. Moreover, HIIT training has the same capability as peak (high level) exercise in maximum oxygen uptake and utilization and is able to achieve max VO2 in a shorter period of time compared to continuous exercise (Baquet et al., 2010). In addition, HIIT training has been shown to be effective in increasing aerobic capacity and memory strength in children (Tottori et al., 2019). Moreover, HIIT training conducted over a longer period of 12 weeks effectively increased oxygen dissipation by 18 percent (Dunn, 2009). While Samuel, Zavdy et.al (2017) reported that high-intensity physical training improves cognitive ability in terms of memory and concentration of children. Smith et al (2015), meanwhile, proved that aerobic exercise can improve the strength of memory and concentration of children among students aged 8 to 12 years.

HIIT training increases aerobic capacity among the obese and overweight children (Yin, Zhou, \& Lan, 2020; Cvetković et al., 2018; Delgado-Floody et al., 2019; DelgadoFloody et al., 2018). The findings of Jeon \& Ha (2017) study are also in line with this study where high-intensity physical training among the male students improved short-term memory strength and concentration. Not only that, HIIT training improves the performance of brain executive function and adolescent cardiovascular fitness (Kujach et al., 2018). Besides that, Delgado-Floody et al., 2018 proved that 22 weeks of HIIT training in Physical education increases aerobic capacity and reduces body composition in children. The study of ZapataLamana et al., 2019 stated that HIIT training can be used as a reliable and time-saving alternative to improve children's cardiovascular fitness while in school.

However, the findings of the study of Alves, Tessaro et. al (2014), are not in line with the findings of the study because there is no positive relationship in the aspect of short-term memory with HIIT intervention training for 7 days for a period of 20 minutes. Furthermore, the study of Costigan et al (2016), is not in line with this study where HIIT training in school for 8 weeks had only a slight improvement on cognitive function among adolescents. These findings may be influenced by the fact that the duration of HIIT training for 8 weeks is not enough to have a productive effect on the cognitive function of brain. Training duration and intensity are important factors in determining the effectiveness of HIIT training on memory strength and aerobic capacity. Other than that, this 4-week HIIT training improved the cardiovascular fitness and memory of the children on the treatment group (Tottori et.al 2019). Based on the study of Lambrick, Westrupp, Kaufmann, Stoner and Faulkner (2016), high-intensity game training for 6 weeks has a positive effect on aerobic capacity in children. Meanwhile et al (2014), reported that high-intensity training for two weeks is sufficient to increase aerobic capacity among adolescents aged between 14 to 16 years. Indeed, highintensity aerobic exercise for extended periods of time i.e. from weeks to months improves brain cognitive function (Northey et al., 2017; Landrigan et al., 2020). 


\section{Conclusion}

The strength of memory and concentration is the important aspect to make sure the academic excellence of students. The findings of this study show that HIIT training programme using IFITTKIDS Module improves memory strength, concentration and aerobic capacity among 11year-old school children. For future studies researchers can apply HIIT-guided games with a shorter duration in Physical Education to see its effects on aerobic capacity and other cognitive functions such as cognitive flexibility. This IFITTKIDS module can be used as a flexible and time-saving training programme to make children's aerobic fitness and memory strength while in school.

\section{Acknowledgement}

I thank Siti Hartini Azmi, and Norhazira Rahim for reading and offering comments on an earlier draft.

\section{Corresponding Author}

Vadivelan Lohonathan

Department of Health Sciences, Faculty of Sports Science and Coaching, Sultan Idris Education University (UPSI), 35900 Tanjung Malim, Perak, Malaysia.

Email: vadivelanphd494@gmail.com

\section{References}

Abraham, A., George, V. M., \& Kunnath, S. (2016). Auditory Short Term Memory and Academic Achievement in Normal School Going Children. International Journal of Health Sciences \& Research, 6(1), 480-483.

Alves, C. R., Tessaro, V. H., Teixeira, L. A., Murakava, K., Roschel, H., Gualano, B., \& Takito, M. Y. (2014). Influence of Acute High-Intensity Aerobic Interval Exercise Bout on Selective Attention and Short-Term Memory Tasks. Perceptual and Motor Skills, 118(1), 63-72. https://doi.org/10.2466/22.06.pms.118k10w4

Awang, Z. (2012). Strategi pengajaran mata pelajaran Pendidikan Jasmani yang berkesan.

(Tesis sarjana tidak diterbitkan). Universiti Malaya, Malaysia.

Bartlett, J. D., Close, G. L., MacLaren, D. P., Gregson, W., Drust, B., \& Morton, J. P. (2011). High-intensity interval running is perceived to be more enjoyable than moderateintensity continuous exercise: implications for exercise adherence. Journal of Sports Sciences, 29(6), 547-553.

Bass, R. W., Brown, D. D., Laurson, K. R., \& Coleman, M. M. (2013). Physical fitness and academic performance in middle school students. Acta Paediatrica, 102(8), 832-837. https://doi.org/10.1111/apa.12278

Barker, A. R., Day, J., Smith, A., Bond, B., \& Williams, C. A. (2014). The influence of 2 weeks of low-volume high-intensity interval training on health outcomes in adolescent boys. Journal of Sports Sciences, 32(8), 757-765. https://doi.org/10.1080/02640414.2013.853132

Baquet, G., Gamelin, F. Ç.-X., Mucci, P., Thévenet, D., Van Praagh, E., \& Berthoin, S. (2010). Continuous vs. interval aerobic training in 8- to 11-year-old children. Journal of Strength and Conditioning Research, 24(5), 1381-1388. https://doi.org/10.1519/jsc.0b013e3181d1575a

Berchtold, N. C., Castello, N., \& Cotman, C. W. (2010). Exercise and time-dependent benefits to learning and memory. Neuroscience, 167(3), 588-597. 
https://doi.org/10.1016/j.neuroscience.2010.02.050

Buchheit, M., \& Laursen, P. B. (2013). High-intensity interval training, solutions to the programming puzzle. Sports Medicine, 43(5), 313-338. doi:10.10007/s40279-0130029$x$

Buck, S. M., Hillman, C. H., \& Castelli, D. M. (2008). The relation of aerobic fitness TO Stroop task performance in preadolescent children. Medicine \& Science in Sports \& Exercise, 40(1), 166-172. https://doi.org/10.1249/mss.0b013e318159b035

Burgomaster, K. A., Howarth, K. R., Phillips, S. M., Rakobowchuk, M., MacDonald, M. J., McGee, S. L., \& Gibala, M. J. (2008). Similar metabolic adaptations during exercise after low volume sprint interval and traditional endurance training in humans. The Journal of Physiology, 586(1), 151-160

Burns, R. D., Hannon, J. C., Allen, B. M., \& Brusseau, T. A. (2014). Convergent validity of The One-Mile run and PACER VO2max prediction models in middle school students. SAGE Open, 4(1), 215824401452542. https://doi.org/10.1177/2158244014525420

Canepa, P., Pedullà, L., Bisio, A., Ruggeri, P., \& Bove, M. (2020). Is the 12 minute-walk/run test a predictive index of cognitive fitness in young healthy individuals? A pilot study on aerobic capacity and working memory in a real-life scenario. Neuroscience Letters, 728, 134983. https://doi.org/10.1016/j.neulet.2020.134983

Carlson, S. A., Fulton, J. E., Lee, S. M., Maynard, L. M., Brown, D. R., Kohl, H. W., \& Dietz, W. H. (2008). Physical Education and Academic Achievement in Elementary School: Data From the Early Childhood Longitudinal Study. American Journal of Public Health, 98(4), 721-727. https://doi.org/10.2105/ajph.2007.117176

Curlik, D. M., \& Shors, T. J. (2013). Training your brain: Do mental and physical (map) training enhance cognition through the process of neurogenesis in the hippocampus? Neuropharmacology, 64, 506-514. https://doi.org/10.1016/j.neuropharm.2012.07.027

Chang, Y. K., Labban, J. D., Gapin, J. I., \& Etnier, J. L. (2012). The effects of acute exercise on cognitive performance: A meta-analysis. Brain Research, 1453, 87-101. https://doi.org/10.1016/j.brainres.2012.02.068

Chandler, R. M., \& Stringer, A. J. (2020). A Comprehensive Exploration into Utilizing HighIntensity Interval Training (HIIT) in Physical Education Classes. Journal of Physical Education, Recreation \& Dance, 91(1), 14-23. https://doi.org/10.1080/07303084.2019.1679296

Castelli, D. M., Hillman, C. H., Buck, S. M., \& Erwin, H. E. (2007). Physical Fitness and academic achievement in third- and fifth-grade students. Journal of Sport and Exercise Psychology, 29(2), 239-252. https://doi.org/10.1123/jsep.29.2.239

Chaddock, L., Erickson, K. I., Prakash, R. S., Kim, J. S., Voss, M. W., VanPatter, M., Pontifex, M. B., Raine, L. B., Konkel, A., Hillman, C. H., Cohen, N. J., \& Kramer, A. F. (2010). A neuroimaging investigation of the association between Aerobic Fitness, hippocampal volume, and memory performance in Preadolescent Children. Brain Research, 1358, 172-183. https://doi.org/10.1016/j.brainres.2010.08.049

Chaddock, L., Pontifex, M. B., Hillman, C. H., \& Kramer, A. F. (2011). A review of the relation of aerobic fitness and physical activity to brain structure and function in children. Journal of the International Neuropsychological Society, 17(6), 975-985. https://doi.org/10.1017/s1355617711000567

Chun, D. M., Corbin, C. B., \& Pangrazi, R. P. (2000). Validation of criterion-referenced standards for the mile run and progressive aerobic cardiovascular endurance tests. Research Quarterly for Exercise and Sport, 71(2), 125-134. 
https://doi.org/10.1080/02701367.2000.10608890

Costigan, S.A.; Eather, N.; Plotnikoff, R.C.; Hillman, C.H.; Lubans, D.R. (2016). High-intensity interval training for cognitive and mental health in adolescents. Medicine \& Science in Sports \& Exercise, 48(10), 1985-1993.

https://doi.org/10.1249/mss.0000000000000993

Crova, C., Struzzolino, I., Marchetti, R., Masci, I., Vannozzi, G., Forte, R., \& Pesce, C. (2013). Cognitively challenging physical activity benefits executive function in overweight children. Journal of Sports Sciences, 32(3), 201-211.

https://doi.org/10.1080/02640414.2013.828849

Cvetković, N., Stojanović, E., Stojiljković, N., Nikolić, D., Scanlan, A. T., \& Milanović, Z. (2018). Exercise training in overweight and obese children: Recreational football and highintensity interval training provide similar benefits to physical fitness. Scandinavian Journal of Medicine \& Science in Sports, 28, 18-32. https://doi.org/10.1111/sms.13241

Davis, C. L., Tomporowski, P. D., McDowell, J. E., Austin, B. P., Miller, P. H., Yanasak, N. E., Allison, J. D., \& Naglieri, J. A. (2011). Exercise improves executive function and achievement and alters brain activation in overweight children: A randomized, controlled trial. Health Psychology, 30(1), 91-98. https://doi.org/10.1037/a0021766

Déry, N., Pilgrim, M., Gibala, M., Gillen, J., Wojtowicz, J. M., MacQueen, G., \& Becker, S. (2013). Adult hippocampal neurogenesis reduces memory interference in humans: Opposing effects of aerobic exercise and depression. Frontiers in Neuroscience, 7. https://doi.org/10.3389/fnins.2013.00066

Delgado-Floody, P., Espinoza-Silva, M., García-Pinillos, F., \& Latorre-Román, P. (2018). Effects of 28 weeks of high-intensity interval training during physical education classes ON cardiometabolic risk factors in Chilean schoolchildren: A pilot trial. European Journal of Pediatrics, 177(7), 1019-1027. https://doi.org/10.1007/s00431-018-3149-3

Delgado-Floody, P., Latorre-Román, P., Jerez-Mayorga, D., Caamaño-Navarrete, F., \& GarcíaPinillos, F. (2019). Feasibility of incorporating high-intensity interval training into physical education programs to improve body composition and cardiorespiratory capacity of overweight and obese children: A systematic review. Journal of Exercise Science \& Fitness, 17(2), 35-40. https://doi.org/10.1016/j.jesf.2018.11.003

Dobbins, M., Husson, H., DeCorby, K., \& LaRocca, R. L. (2013). School-based physical activity programs for promoting physical activity and fitness in children and adolescents aged 6 to 18. Cochrane Database of Systematic Reviews. https://doi.org/10.1002/14651858.cd007651.pub2

Donnelly, J. E., Hillman, C. H., Castelli, D., Etnier, J. L., Lee, S., Tomporowski, P., Lambourne, K., \& Szabo-Reed, A. N. (2016). Physical activity, fitness, cognitive function, and academic achievement in children. Medicine \& Science in Sports \& Exercise, 48(6), 11971222. https://doi.org/10.1249/mss.0000000000000901

Drollette, E. S., Scudder, M. R., Raine, L. B., Davis Moore, R., Pontifex, M. B., Erickson, K. I., \& Hillman, C. H. (2015). The sexual dimorphic association of cardiorespiratory fitness to working memory in children. Developmental Science, 19(1), 90-108. https://doi.org/10.1111/desc.12291

Dunn, S. L. (2009). Effects of exercise and dietary intervention on metabolic syndrome markers of inactive premenopausal women (Doctoral dissertation, University of New South Wales). 
El-Sayes, J., Harasym, D., Turco, C. V., Locke, M. B., \& Nelson, A. J. (2018). Exercise-Induced Neuroplasticity: A Mechanistic Model and Prospects for Promoting Plasticity. The Neuroscientist, 25(1), 65-85. https://doi.org/10.1177/1073858418771538

Ericsson, I. (2008). Motor skills, attention and academic achievements. An intervention study in school years 1-3. British Educational Research Journal, 34(3), 301-313. https://doi.org/10.1080/01411920701609299

Erickson, K. I., Hillman, C. H., \& Kramer, A. F. (2015). Physical activity, brain, and cognition. Current Opinion in Behavioral Sciences, 4, 27-32. https://doi.org/10.1016/j.cobeha.2015.01.005

Esteban-Cornejo, I., Tejero-Gonzalez, C. M., Sallis, J. F., \& Veiga, O. L. (2015). Physical activity and cognition in adolescents: A systematic review. Journal of Science and Medicine in Sport, 18(5), 534-539. https://doi.org/10.1016/j.jsams.2014.07.007

Farmer, J., Zhao, X., van Praag, H., Wodtke, K., Gage, F. H., \& Christie, B. R. (2004). Effects of voluntary exercise on synaptic plasticity and gene expression in the dentate gyrus of adult male sprague-dawley rats in vivo. Neuroscience, 124(1), 71-79.

https://doi.org/10.1016/j.neuroscience.2003.09.029

Frazão, D. T., de Farias Junior, L. F., Dantas, T. C., Krinski, K., Elsangedy, H. M., Prestes, J., Hardcastle, S. J., \& Costa, E. C. (2016). Feeling of Pleasure to High-Intensity Interval Exercise Is Dependent of the Number of Work Bouts and Physical Activity Status. PLOS ONE, 11(3), 1-16. https://doi.org/10.1371/journal.pone.0152752

Gallotta, M. C., Emerenziani, G. P., Iazzoni, S., Meucci, M., Baldari, C., \& Guidetti, L. (2015). Impacts of coordinative training on normal weight and overweight/obese children's attentional performance. Frontiers in Human Neuroscience, 9. https://doi.org/10.3389/fnhum.2015.00577

Gibala, M. J., \& McGee, S. L. (2008). Metabolic adaptations to short-term high-intensity interval training: a little pain for a lot of gain? Exercise and Sport Sciences Reviews, 36(2), 58-63.

Gibala, M. J., Little, J. P., Van Essen, M., Wilkin, G. P., Burgomaster, K. A., Safdar, A., Raha, S., \& Tarnopolsky, M. A. (2006). Short-term sprint intervalversustraditional endurance training: Similar initial adaptations in human skeletal muscle and exercise performance. The Journal of Physiology, 575(3), 901-911. https://doi.org/10.1113/jphysiol.2006.112094

Hillman, C. H., Erickson, K. I., \& Kramer, A. F. (2008). Be smart, exercise your heart: Exercise effects on brain and cognition. Nature Reviews Neuroscience, 9(1), 58-65. https://doi.org/10.1038/nrn2298

Hwang, C. L., Wu, Y. T., \& Chou, C. H. (2011). Effect of aerobic interval training on exercise capacity and metabolic risk factors in people with cardiometabolic disorders: a meta-analysis. Journal of Cardiopulmonary Rehabilitation and Prevention, 31(6), 378-385.

Jeon, Y. K., \& Ha, C. H. (2017). The effect of exercise intensity on brain derived neurotrophic factor and memory in adolescents. Environmental Health and Preventive Medicine, 22(1), 1-6. https://doi.org/10.1186/s12199-017-0643-6

Kao, S. C., Drollette, E. S., Ritondale, J. P., Khan, N., \& Hillman, C. H. (2018). The acute effects of high-intensity interval training and moderate-intensity continuous exercise on declarative memory and inhibitory control. Psychology of Sport and Exercise, 38, 90-99. https://doi.org/10.1016/j.psychsport.2018.05.011 
Kao, S. C., Cadenas-Sanchez, C., Shigeta, T., Walk, A., Chang, Y. K., Pontifex, M., \& Hillman, C. (2019). A systematic review of physical activity and cardiorespiratory fitness on $\mathrm{p} 3 \mathrm{~b}$. Psychophysiology, 57(7), 1-40. https://doi.org/10.1111/psyp.13425

Kao, S. C., Wang, C.-H., \& Hillman, C. H. (2020). Acute effects of aerobic exercise on response variability and neuroelectric indices during a serial n-back task. Brain and Cognition, 138, 105508. https://doi.org/10.1016/j.bandc.2019.105508

Ketelhut, S., Kircher, E., Ketelhut, S. R., Wehlan, E., \& Ketelhut, K. (2020). Effectiveness of multi-activity, high-intensity interval training in school-aged children. International Journal of Sports Medicine, 41(04), 227-232. https://doi.org/10.1055/a-1068-9331

Kilpatrick, M. W., Jung, M. E., \& Little, J. P. (2014). High-intensity interval training: a review of physiological and psychological responses. ACSM's Health \& Fitness Journal, 18(5), 11 16.

Kujach, S., Byun, K., Hyodo, K., Suwabe, K., Fukuie, T., Laskowski, R., Dan, I., \& Soya, H. (2018). A transferable high-intensity intermittent exercise improves executive performance in association with dorsolateral prefrontal activation in young adults. Neurolmage, 169, 117-125. https://doi.org/10.1016/j.neuroimage.2017.12.003

Khan, N. A., \& Hillman, C. H. (2014). The Relation of Childhood Physical Activity and Aerobic Fitness to Brain Function and Cognition: A Review. Pediatric Exercise Science, 26(2), 138-146. https://doi.org/10.1123/pes.2013-0125

Knaepen, K., Goekint, M., Heyman, E. M., \& Meeusen, R. (2010). Neuroplasticity - exerciseinduced response of peripheral brain-derived neurotrophic factor. Sports Medicine, 40(9), 765-801. https://doi.org/10.2165/11534530-000000000-00000

Koutsandreou, F., Wegner, M., Niemann, C., \& Budde, H. (2016). Effects of Motor versus Cardiovascular Exercise Training on Children's Working Memory. Medicine \& Science in Sports \& Exercise, 48(6), 1144-1152. https://doi.org/10.1249/mss.0000000000000869

Lin, C. C., Hsieh, S. S., Chang, Y. K., Huang, C. J., Hillman, C., \& Hung, T. M. (2021). Up-regulation of proactive control is associated with beneficial effects of a childhood gymnastics program on response preparation and working memory. Brain and Cognition, 149, 105695. https://doi.org/10.1016/j.bandc.2021.105695

Lambrick, D., Westrupp, N., Kaufmann, S., Stoner, L., \& Faulkner, J. (2016). The effectiveness of a high-intensity games intervention on improving indices of health in young children. Journal of sports sciences, 34(3), 190-198.

Doi: 10.1080/02640414.2015.1048521

Landrigan, J. F., Bell, T., Crowe, M., Clay, O., \& Mirman, D. (2020). Lifting cognition: A metaanalysis of effects of resistance exercise on cognition. Psychological Research, 84(5), 1167-1183. https://doi.org/10.1007/s00426-019-01145-x

Little, J. P., Gillen, J. B., Percival, M. E., Safdar, A., Tarnopolsky, M. A., Punthakee, Z., ... \& Gibala, M. J. (2011). Low-volume high-intensity interval training reduces hyperglycemia and increases muscle mitochondrial capacity in patients with type 2 diabetes. Journal of Applied Physiology, 111(6), 1554-1560.

Lonsdale, C., Rosenkranz, R. R., Peralta, L. R., Bennie, A., Fahey, P., \& Lubans, D. R. (2013). A systematic review and meta-analysis of interventions designed to increase moderateto-vigorous physical activity in school physical education lessons. Preventive Medicine, 56(2), 152-161. https://doi.org/10.1016/j.ypmed.2012.12.004

Ludyga, S., Herrmann, C., Mücke, M., Andrä, C., Brand, S., Pühse, U., \& Gerber, M. (2018). Contingent Negative Variation and Working Memory Maintenance in Adolescents with Low and High Motor Competencies. Neural Plasticity, 2018, 1-9. 
https://doi.org/10.1155/2018/9628787

Malina, R. M. (1996). Tracking of physical activity and physical fitness across the lifespan. Research Quarterly for Exercise and Sport, 67(sup3), 48-57. https://doi.org/10.1080/02701367.1996.10608853

Milanović, Z., Sporiš, G., \& Weston, M. (2015). Effectiveness of high-intensity interval training (HIT) and continuous endurance training for VO2max improvements: a systematic review and meta-analysis of controlled trials. Sports Medicine, 45, 14691481.

Moreau, D., \& Chou, E. (2019). The acute effect of high-intensity exercise on executive function: A meta-analysis. Perspectives on Psychological Science, 14(5), 734-764. https://doi.org/10.1177/1745691619850568

Moreau, D., Kirk, I. J., \& Waldie, K. E. (2017). High-intensity training enhances executive function in children in a randomized, placebo-controlled trial. ELife, 6, 2-26. https://doi.org/10.7554/elife.25062

Mura, G., Vellante, M., Nardi, A., Machado, S., \& Carta, M. (2015). Effects of school-based physical activity interventions on cognition and academic achievement: A systematic review. CNS \& Neurological Disorders - Drug Targets, 14(9), 1194-1208. https://doi.org/10.2174/1871527315666151111121536

Northey, J. M., Cherbuin, N., Pumpa, K. L., Smee, D. J., \& Rattray, B. (2017). Exercise interventions for cognitive function in adults older THAN 50: A systematic review with meta-analysis. British Journal of Sports Medicine, 52(3), 154-160. https://doi.org/10.1136/bjsports-2016-096587

Papp, K. V., Kaplan, R. F., Springate, B., Moscufo, N., Wakefield, D. B., Guttmann, C. R., \& Wolfson, L. (2013). Processing speed in normal aging: Effects of white matter hyperintensities and hippocampal volume loss. Aging, Neuropsychology, and Cognition, 21(2), 197-213. https://doi.org/10.1080/13825585.2013.795513

Pesce, C., Crova, C., Marchetti, R., Struzzolino, I., Masci, I., Vannozzi, G., \& Forte, R. (2013). Searching for cognitively optimal challenge point in physical activity for children with typical and atypical motor development. Mental Health and Physical Activity, 6(3), 172180. https://doi.org/10.1016/j.mhpa.2013.07.001

Pesce, C., Masci, I., Marchetti, R., Vazou, S., Saakslahti, A., \& Tomporowski, P. D. (2016). Deliberate play and preparation jointly benefit motor and cognitive development: Mediated and moderated effects. Frontiers in Psychology, 7, 155. doi:10.3389/fpsyg.2015.00349

Pontifex, M. B., Raine, L. B., Johnson, C. R., Chaddock, L., Voss, M. W., Cohen, N. J., Kramer, A. F., \& Hillman, C. H. (2011). Cardiorespiratory fitness and the flexible modulation of cognitive control in Preadolescent Children. Journal of Cognitive Neuroscience, 23(6), 1332-1345. https://doi.org/10.1162/jocn.2010.21528

Postle, B. R. (2006). Working memory as an emergent property of the mind and brain. Neuroscience, 139(1), 23-38. https://doi.org/10.1016/j.neuroscience.2005.06.005

Postle, B. R. (2016). How does the brain keep information "in mind"? Current Directions in Psychological Science, 25(3), 151-156. https://doi.org/10.1177/0963721416643063

Raine, L. B., Scudder, M. R., Saliba, B. J., Kramer, A. F., \& Hillman, C. (2016). Aerobic fitness and Context processing in preadolescent children. Journal of Physical Activity and Health, 13(1), 94-101. https://doi.org/10.1123/jpah.2014-0468

Rasberry, C. N., Lee, S. M., Robin, L., Laris, B. A., Russell, L. A., Coyle, K. K., \& Nihiser, A. J. (2011). The association between school-based physical activity, including physical 
education, and academic performance: A systematic review of the literature. Preventive Medicine, 52. https://doi.org/10.1016/j.ypmed.2011.01.027

Rassovsky, Y., \& Alfassi, T. (2019). Attention improves during physical exercise in individuals with ADHD. Frontiers in Psychology, 9:2747. https://doi.org/10.3389/fpsyg.2018.02747

Rao, R. M., Vhavle, S. P., \& Manjunath, N. K. (2019). Comparison of yoga versus physical exercise on executive function, attention, and working memory in adolescent schoolchildren: A randomized controlled trial. International Journal of Yoga, 12(2), 172. https://doi.org/10.4103/ijoy.ijoy_61_18

Richardson, J. T. (2007). Measures of short-term memory: a historical review. Cortex, 43(5), 635-650.

Samuel, R. D., Zavdy, O., Levav, M., Reuveny, R., Katz, U., \& Dubnov-Raz, G. (2017). The Effects of Maximal Intensity Exercise on Cognitive Performance in Children. Journal of Human Kinetics, 57(1), 85-96. https://doi.org/10.1515/hukin-2017-0050

Sujatha, B., Alagesan, J., Pavithra, B., Pavithra, P., \& Rayna, A. B. S. (2020). Effectiveness of Aerobic Exercise on Short-Term Memory and Sustained Attention among School Students. Biomedicine, 40(2), 246-250.

Suminski, R. R., Ryan, N. D., Poston, C. S., \& Jackson, A. S. (2004). Measuring aerobic fitness of Hispanic Youth 10 to 12 years of age. International Journal of Sports Medicine, 25(1), 61-67. https://doi.org/10.1055/s-2003-45230

Scherder, E., Scherder, R., Verburgh, L., Königs, M., Blom, M., Kramer, A. F., \& Eggermont, L. (2014). Executive functions of sedentary elderly may benefit from walking: A systematic review and meta-analysis. The American Journal of Geriatric Psychiatry, 22(8), 782-791. https://doi.org/10.1016/j.jagp.2012.12.026

Schmidt, M., Jäger, K., Egger, F., Roebers, C. M., \& Conzelmann, A. (2015). Cognitively engaging chronic physical activity, but not aerobic exercise, affects executive functions in primary school children: A group-randomized controlled trial. Journal of Sport and Exercise Psychology, 37(6), 575-591. https://doi.org/10.1123/jsep.2015-0069

Tomporowski, P. D., Lambourne, K., \& Okumura, M. S. (2011). Physical activity interventions and children's mental function: An introduction and overview. Preventive Medicine, 52, S3-S9. https://doi.org/10.1016/j.ypmed.2011.01.028

Tottori, N., Morita, N., Ueta, K., \& Fujita, S. (2019). Effects of High Intensity Interval Training on Executive Function in Children Aged 8-12 Years. International Journal of Environmental Research and Public Health, 16(21), 4127.

https://doi.org/10.3390/ijerph16214127

Tjønna, A. E., Stølen, T. O., Bye, A., Volden, M., Slørdahl, S. A., Ødegård, R., \& Wisløff, U. (2009). Aerobic interval training reduces cardiovascular risk factors more than a multi treatment approach in overweight adolescents. Clinical Science, 116(4), 317-326.

Van der Niet, A. G., Smith, J., Scherder, E. J. A., Oosterlaan, J., Hartman, E., \& Visscher, C. (2015). Associations between daily physical activity and executive functioning in primary school-aged children. Journal of Science and Medicine in Sport, 18(6), 673-677. https://doi.org/10.1016/j.jsams.2014.09.006

Van der Niet, A. G., Smith, J., Oosterlaan, J., Scherder, E. J. A., Hartman, E., \& Visscher, C. (2016). Effects of a cognitively demanding aerobic intervention during recess on children's physical fitness and executive functioning. Pediatric Exercise Science, 28(1), 64-70. https://doi.org/10.1123/pes.2015-0084

Vazou, S., Pesce, C., Lakes, K., \& Smiley-Oyen, A. (2016). More than one road leads to Rome: A narrative review and meta-analysis of physical activity Intervention effects on 
cognition in youth. International Journal of Sport and Exercise Psychology, 17(2), 153178. https://doi.org/10.1080/1612197x.2016.1223423

Wambach, D., Lamar, M., Swenson, R., Penney, D. L., Kaplan, E., \& Libon, D. J. (2011). Digit span. Encyclopedia of clinical neuropsychology, 844-849.

Wisløff, U., Støylen, A., Loennechen, J. P., Bruvold, M., Rognmo, Ø., Haram, P. M., \& Videm, V. (2007). Superior cardiovascular effect of aerobic interval training versus moderate continuous training in heart failure patients a randomized study. Circulation, 115(24), 3086-3094

Woods, D. L., Kishiyama, M. M., Yund, E. W., Herron, T. J., Edwards, B., Poliva, O., \& Reed, B. (2011). Improving digit span assessment of short-term verbal memory. Journal of clinical and experimental neuropsychology, 33(1), 101-111.

Yin, J., Zhou, Z., \& Lan, T. (2020). High-intensity interval training versus moderate-intensity continuous training on health outcomes for children and adolescents: A meta-analysis of randomized controlled trials. BioMed Research International, 2020, 1-18. https://doi.org/10.1155/2020/9797439

Youngjohn, J. R., Larrabee, G. J., \& Crook, T. H. (1992). Test-retest reliability of computerized, everyday memory measures and traditional memory tests. Clinical Neuropsychologist, 6(3), 276-286. https://doi.org/10.1080/13854049208404129

Zapata-Lamana, R., Cuevas, C. I., Fuentes, V., Espindola, S. C., Romero, P. E., Sepulveda, C., \& Monsalves-Alvarez, M. (2019). HIITing health in School: Can high intensity interval training be a useful and reliable tool for health on a School-Based Enviroment? A systematic review. International Journal of School Health, 6(3), 1-10. https://doi.org/10.5812/intjsh.89829 